\title{
Patients' Experiences after Cognitive Behavior Group Therapy: From Anxiety to Feelings of Perceived Security
}

\author{
Catharina Abrahamsson', Bodil Nordling1, Clive S. Michelsen², Torsten Norlander ${ }^{1,2^{*}}$ \\ ${ }^{1}$ Center for Research and Development, Evidens University College, Göteborg, Sweden \\ ${ }^{2}$ Division of Research, Sciens College, Malmö, Sweden \\ Email: *at.norlander@mailbox.tele2.se
}

How to cite this paper: Abrahamsson, C., Nordling, B., Michelsen, C. S., \& Norlander, T. (2018). Patients' Experiences after Cognitive Behavior Group Therapy: From Anxiety to Feelings of Perceived Security. Psychology, 9, 1176-1193.

https://doi.org/10.4236/psych.2018.95072

Received: March 13, 2018

Accepted: May 28, 2018

Published: May 31, 2018

Copyright $(9) 2018$ by authors and Scientific Research Publishing Inc. This work is licensed under the Creative Commons Attribution International License (CC BY 4.0).

http://creativecommons.org/licenses/by/4.0/

\begin{abstract}
The vast majority of qualitative studies that examined the patient's own experiences of cognitive psychotherapy are about experiences from individual therapy. Studies dedicated to investigating how patients experience group treatment are more unusual, although such treatment contains components lacking in individual therapy. The purpose of the current study was to investigate which components and interventions have been considered significant by patients who achieved diagnostic improvements after performing Cognitive Behavior Group Therapy (CBGT) for individuals with clinical anxiety. Participants consisted of seven patients ( 2 men and 5 women) aged 21 - 61 whom took part in CBGT for patients with anxiety problems. Respondents were recruited from seven treatment groups in southwestern Sweden. Prerequisites to selection were that prior to treatment, they were diagnosed as having clinical anxiety, and that after treatment, their diagnosis of clinical anxiety had been removed. For analysis of data, the Empirical Phenomenological Psychological (EPP) method (Karlsson, 1995) was used. Results showed that respondents described their anxiety as a lack of security, and that their treatment increased their feelings of security. Three themes emerged which were important for creating security: 1) Sharing with others, 2) Knowledge, and 3) Structure. Further analysis indicated that a security process was established where the perceived security of the group, "outside the individual", could be moved to "inside the individual."
\end{abstract}

\section{Keywords}

Anxiety, CBT, Depression, Feelings of Perceived Security, Group Treatment

\section{Introduction}

Mental ill-health with anxiety and depression is one of the most common rea- 
sons for people to end up outside the labor market (World Health Organization, 2014). Unless these persons receive adequate help, there is a high risk of psychosomatic deterioration in the form of long-term disease states and persistent functional impairments (Angantyr, Rimner, Nordén, \& Norlander, 2015). Cognitive Behavior Therapy (CBT) has strong research support, and has been proven to be cost-effective (Butler, Chapman, Forman, \& Beck, 2006), and therefore the demand for such treatment increases (Jervelycke, Larsson, \& Norlander, 2017). CBT is recommended for treatment of anxiety and depression in a number of countries, e.g., Sweden, Canada and the United Kingdom (Söchting, 2014). CBT is a structured and action-oriented therapy with concrete goals (Hawley, Padesky, Hollon, Mancuso, Laposa, Brozina, \& Segal, 2017) focusing on finding triggering and maintenance factors in order to change the thoughts and behaviors of anxiety and depression. The treatment usually involves home assignments, experiments and exposures, usually in the environment in which the patient is located. Whether or not group treatment is as effective as individual treatment, due to time and cost reasons, group therapy was used in the treatment of depression and has been addressed in several studies as far back as the 1970s (Bieling, McMaster, Hamilton, McCabe, Antony, \& Antony, 2006). In the early 1990s, the abbreviation CBGT, Cognitive Behavior Group Therapy was coined (Heimberg, Salzman, Holt, \& Blendell, 1993).

An early study (Shaffer, Shapiro, Sank, \& Coghlan, 1981) showed that regardless of whether the CBT therapy was conducted in groups or individually, similar treatment effects were achieved in reducing symptoms of depression and anxiety. It was also apparent that, from cost perspective, group therapy was better for anxiety and depression, which is in line with several recent studies showing that group therapy may offer significant cost savings and efficiency gains without compromising on quality of care (e.g., Bennett-Levy, Richards, \& Farrand, 2010). A recent analysis (Söchting, 2014) of comparative studies regarding group therapy and individual therapy showed that people with generalized anxiety disorder and panic disorder had a large exchange of the group format, and it was also found that the discontinuation of ongoing individual treatment was more extensive compared to group treatment. In addition, treatment outcomes appear to be unaffected by patients having different diagnoses within the anxiety spectrum (Chamberlain \& Norton, 2013). CBT in groups can often be offered at less than half the cost of individual treatment and one-fourth of the cost of medical treatment (Söchting, 2014), which would be a contributing factor to the increased interest from the care providers.

According to Söchting (2014), the unique advantage of CBGT is that the group interaction breaks social isolation, thereby reducing the feeling of belonging to a marginalized and stigmatized group. Unlike the individual therapy, participants receive a greater sense of meaning and context. The interaction between participants offers important opportunities for learning and information exchange. The social system of the group becomes part of the therapeutic intervention (Dugas, Ladouceur, Léger, Freeston, Langolis, Provencher, \& Boisvert, 2003) and when a 
therapy group develops to an increased degree of openness and trust, it becomes an arena for experiences. The group offers opportunities for a "social restart". Unlike individual therapies, group therapy becomes more like real life, because it constitutes of fellow people sharing the same conditions and together trying out what works (Bieling et al., 2006). It is therefore possible to use the experiences gained in the group to develop new ways of dealing with the outside world.

A report on Evidence-Based Practice in psychology (American Psychological Association, 2006) emphasized the importance of an integration of science and practice where one of the points was that "qualitative research can be used to describe the subjective, lived experiences of people, including participants in psychotherapy" (p. 274), which may lead to the identification of parameters that can improve treatment outcomes. It is in line with the qualitative premise that it is the patient himself/herself who is the best judge of his/her process and experience (Lilja, Broberg, Norlander, \& Broberg, 2015). Malterud (2001) proposes not to consider quantitative and qualitative strategies as incompatible, but should be seen as complementary to each other because the underlying principles have much in common. However, Malterud believes that qualitative inquiry can be improved by highlighting issues of reliability and validity in the qualitative context. Binder and associates (Binder, Holgersen, \& Nielsen, 2009) interviewed ten patients who felt they had been helped by psychotherapy. Four themes emerged regarding the participants' views of what was active in beneficial process: 1) to be in relationship with a wise, warm and competent professional therapist, 2) to be in an ongoing relationship when one is suffering and has feelings of inner discontinuity, 3) to get ones assumptions and beliefs about oneself and ones relationships corrected and finally 4) to create new meaning and see new patterns. These findings are in line with several other qualitative studies (e.g., Carey, Carey, Stalker, Mullan, Murray, \& Spratt, 2007).

The vast majority of qualitative studies that examined the patient's own experiences of cognitive psychotherapy are about experiences from individual therapy. Studies dedicated to investigating how patients experience group treatment are more unusual, although such treatment contains components lacking in individual therapy (Söchting, 2014). A qualitative study (Ingvarsson, Nordén, \& Norlander, 2014) aimed to study for the first time patients' own experiences of developing healthy behavior in connection with their participation in group therapy. Five main themes emerged: 1) Roads to healthy behaviors, 2) Comprehensive distancing, 3) Acquiring new proficiencies 4) Generalizing and 5) Healthy behavior and the nature thereof. The five themes were shown to create a causal chain where healthy behavior contributes to a process of change which eventually leads to insights about healthier behavior. However, the study shared a limitation with other similar studies, namely that the results of group therapy were analyzed almost exclusively on an individual basis without the analysis integrating the individual perspective with a group dynamic perspective. There is a great need for qualitative studies which have this analytic integration of perspec- 
tives. The purpose of the current study was to investigate which components and interventions have been considered significant by patients who achieved diagnostic improvements after performing cognitive behavior group therapy for individuals with clinical anxiety.

\section{Method}

\subsection{Participants}

Participants in the current study consisted of seven patients ( 2 men and 5 women) aged 21 - 61 whom took part in CBGT treatment for individuals with anxiety problems. Thus, all participating patients were diagnosed having anxiety, and four of them, had a second diagnosis of depression. Patients were recruited by asking participants from seven treatment groups in southwestern Sweden (Västragötaland county council).

Prerequisites to selection were that prior to treatment, they were diagnosed as having clinical anxiety or depression, and that after treatment, their diagnosis of clinical anxiety and/or depression had been removed. Three of the patients were on sick leave during the treatment (two full-time and one half-time), but at the time of the interview, they had already returned to work fulltime. As for the four participants who were working fulltime during ongoing group treatment, two of these had previously been on sick leave. Hereinafter, the participants in the study will be referred to as respondents.

\subsection{Design}

Group treatment for patients with anxiety, using CBT as a treatment method, was conducted with seven treatment groups from two care centers. Patients were selected on the recommendation of their treating physicians. The group treatment, with approximately 5 - 10 patients in each group, was conducted in seven weekly meetings of 1.5 hours each with a break of 2 - 3 weeks before the last occasion. Each group session had a theme and each time there was also a shorter relaxation or mindfulness exercise. A typical group treatment included the following components: relaxation and mindfulness, planning, implementation and follow-up of behavioral experiments, maintenance and a final evaluation.

\subsection{Implementation of the Data Collection}

A selection, with two prerequisites, was made from participants from the different treatment groups: 1) prior to treatment, they must have had values that, according to HAD (Hospital Anxiety and Depression Scale) (Zigmond \& Snaith, 1983), met the level for the criterion of clinical anxiety ( $\geq 11$ points) and in the presence of depression it also had to be at the criterion of clinical level $(\geq 11$ points), and 2) after group treatment, they should no longer meet the clinical criteria for anxiety ( $\leq 7$ points) or depression ( $\leq 7$ points). For participation in the current study the ten patients whom had reduced their levels most significantly on the HAD scales were approached. Three declined participation. Thus, there 
were seven people, two men and five women who signed up for participation in the study. The proportion of men was well in line with the percentage distribution of men (approximately 30\%) in the treatment groups.

Unstructured interviews were used with only one open question: "You have undergone group treatment for anxiety-what do you feel about it?" Respondents were then allowed share their thoughts and reflections completely freely and spontaneously. Each interview was about 60 minutes long and was recorded in order to be transcribed verbatim into a text document. At the first interview there were two interviewers (first and second authors) and one respondent present, but in the other interviews only one of the interviewers was present together with a respondent. Time to interview differed between 2 and 12 months and was dependent upon the time it took between when patients had finished their group treatment and when they were interviewed. In conjunction with each interview, all respondents were required to complete the HAD, all respondents scored, showed additional improvements.

\subsection{Analysis of Data}

For analysis of data, the Empirical Phenomenological Psychological (EPP) method devised by Karlsson (1995) was used. The EPP applies five steps in the analysis:

- Step one requires that printed interviews are read several times to get an understanding of the material.

- In the second step, the text is analyzed by dividing it into minor meaning units (MU) based on its psychological meaning rather than from the grammatical meaning. In the current study, 610 meaning units were created.

- Step three involves transforming each raw MU into a more abstract language to facilitate explicit communication of implicit meaning structures.

- In the fourth step, transformed MUs were divided into categories that illuminate the phenomenon from different angles and create a new and unique structure for the material aimed at increasing understanding of the phenomenon. In the current study, this resulted in 41 categories, which were then grouped into 9 index categories, i.e., overall categories.

- The fifth and final step involved identifying themes describing the essence of the studied phenomenon. In the current study, two authors searched independently for themes that could cast light on the processes of group treatment. Their results were striking similarly as they found three clearly recurring themes that appeared in all index categories, as well as categories, and were also amply represented at the MU level. This result was then critically reviewed by the other two authors whom arrived at the same conclusion. These themes also enabled a description of the process of the work in the group.

\subsection{Credibility}

To control for reliability of the results, the Norlander Credibility Test (NCT) de- 
vised for phenomenological analyses was used (Norlander, Blom, \& Archer, 2002). In the current study, the test was conducted by randomizing one category from each of the nine index categories, and then another category was added from the remaining categories. From the total of 10 categories, five transformed MUs from each category were randomly drawn. The material was then transferred to three independent assessors and their task consisted of distributing the 50 MUs to the ten categories. The result of the NCT test was that one of the respondents received $66 \%$ coherence as compared to the authors, the other $72 \%$, and the third $76 \%$. This resulted in an average NCT value of 71 which is in line with previously published results (e.g., Edebol, Bood, \& Norlander, 2008; Niklasson, Niklasson, \& Norlander, 2010; Nordén, Eriksson, Kjellgren, \& Norlander, 2012).

\subsection{Ethical Considerations}

The study followed the Swedish rules on ethics and the ethical standards of the World Medical Association's Declaration of Helsinki concerning Ethical Principles of Medical Research Involving Human Subjects. The management at each care unit was informed of the study purposes and gave their permission. In addition, it was clarified for both the management and the patients that participation was entirely voluntary and that the respondents were entitled to discontinue participation in the study at any time without having to give a reason. Furthermore, the respondents were guaranteed confidential treatment and complete anonymity when the results were published. Written informed consent was obtained from the participants. The Ethical Committee at Sciens College examined and approved the study.

\section{Results}

The identified 610 MUs were sorted according to how they fit together which resulted into 41 categories, which in turn could be grouped into 9 index categories. These were: 1) Design of treatment; 2) Conditions before treatment; 3) Conditions during treatment; 4) Experiences of normalization; 5) CBT methods and strategies; 6) Interventions dealing with anxiety; 7) Side effects; 8) Comments on therapy and 9) Conditions after treatment. The 9 index categories are reported within this section. Each category consists of a synopsis, a description of its content. The synopsis contains examples of raw MUs, i.e., the respondents' original formulations without edits. Examples on raw MUs are indicated in italics. The distribution in terms of number of MUs, categories and index categories are shown in Table 1. In the Discussion section we will deal with the typological structures generated through analyzes, i.e., themes, processes and models.

\subsection{Design of Treatment}

Respondents thought it was enough to meet once a week on 6 occasions and that the time for a session was long enough: "Yes, I don't think one could have managed 
Table 1. Overview: Index categories, categories and number of meaning units (MU).

\begin{tabular}{|c|c|c|}
\hline \multirow{2}{*}{$\begin{array}{l}\text { Index categories } \\
\text { 1) Design of treatment }\end{array}$} & \multicolumn{2}{|c|}{ Categories } \\
\hline & 1) & Structure and layout of the groups \\
\hline \multirow[t]{3}{*}{$(53 \mathrm{MU})$} & 2) & Group size \\
\hline & 3) & Patient category \\
\hline & 4) & Individual calls before, during, after \\
\hline \multirow[t]{4}{*}{ 2) Conditions before treatment } & 5) & Attitudes before the start of the group process \\
\hline & 6) & Reflections on getting help earlier \\
\hline & 7) & Life situation and state of health at group start \\
\hline & 8) & Preparations for group therapy \\
\hline \multirow[t]{5}{*}{ 3) Conditions during treatment } & 9) & Experiences during ongoing treatment \\
\hline & 10) & Interaction in the group \\
\hline & 11) & The group as a role model for how to behave \\
\hline & 12) & Confirmation/Validation \\
\hline & 13) & The instructors as group leaders \\
\hline \multirow[t]{5}{*}{ 4) Experiences of normalization } & 14) & Normalization \\
\hline & 15) & My reaction is normal \\
\hline & 16) & Insights on how others feel \\
\hline & 17) & Does the look change when you feel bad? \\
\hline & 18) & $\begin{array}{l}\text { Opportunities to get new perspectives in the group } \\
\text { and to contribute to others with such }\end{array}$ \\
\hline 5) $\mathrm{CBT}$ methods and strategies & 19) & $\begin{array}{l}\text { Work on forms, such as "Situation Analysis" and } \\
\text { "Acceptance" }\end{array}$ \\
\hline \multirow[t]{3}{*}{ (69 MU) } & 20) & Breathing \\
\hline & 21) & Mindfulness and relaxation \\
\hline & 22) & Psycho education - knowledge and facts \\
\hline \multirow{6}{*}{$\begin{array}{l}\text { 6) Interventions dealing with anxiety } \\
\text { (84 MU) }\end{array}$} & 23) & Acceptance \\
\hline & 24) & Own care \\
\hline & 25) & Homework during group time \\
\hline & 26) & Increased knowledge about oneself \\
\hline & 27) & Changed thinking strategies \\
\hline & 28) & Exposure/Stop avoiding \\
\hline \multirow{4}{*}{$\begin{array}{l}\text { 7) Side effects } \\
\text { (52 MU) }\end{array}$} & 29) & Integrity when you want \\
\hline & 30) & Increased openness \\
\hline & 31) & To get support from a relative \\
\hline & 32) & Exercise \\
\hline
\end{tabular}




\section{Continued}

8) Comments on treatment
$\begin{aligned} & \text { 33) Attention to the effect of group treatment } \\ & \text { (64) PU) } \\ & \text { treatment } \\ & \text { 35) Difficulties with group treatment } \\ & \begin{array}{ll}\text { 36) Comparisons between individual treatment versus } \\ \text { group treatment }\end{array} \\ & \begin{array}{ll}\text { 9) Conditions after treatment } & \text { 37) Integration and acceptance } \\ \text { (76 MU) } & \text { 39) Internal changes through feelings of acceptance and } \\ \text { security }\end{array} \\ & \text { 40) Experienced differences after group treatment } \\ & \text { 41) Impediments to improvements }\end{aligned}$

more and I don't think a shorter session would have been better either because ... well, one hour and a half was fine. Because one was quite tired afterwards". It was important to insure that both content and time were well-balanced so that the discussions could be summarized a good conclusion could be reached. The respondents who participated in smaller groups with only 4 - 6 participants expressed that the sessions gave them a feeling of security and that time was sufficient for all. Those whom participated in larger groups (about 7 - 10 participants) described that sometimes it could be difficult for everyone to have equal time as there was an increased risk of a group participant becoming too dominant. All respondents stated that it was rewarding with mixed ages and gender: "Well, it was very ... I think it was rather mixed, there were men and women, different ages ... I was one of the younger ones, absolutely ... Yeah, it was ... you realized they were ordinary people with ordinary jobs having kind of the same sort of problems". An individual telephone call before the start of the group training, was considered by several respondents as helpful, but not necessary. Getting a follow-up telephone call was considered as good, but the wish was that it should have been after a couple of months: "We had a break for a week or two, and I guess not much had happened by that time, it wasn't until later that I started to notice some differences".

\subsection{Conditions before Treatment}

Respondents argued that before group treatment they had considerable problems dealing with stress and anxiety, as well as having disastrous, negative thoughts and they often felt sad and worried: "I sort of haven't been able to handle it, I haven't, like, known what to do with my feelings, I just put them away."|"Otherwise, before, I was just inside that anxiety and didn't know how to get out of it'. All respondents expressed that before the start of the treatment they had doubts about participating in group treatment, since it meant they had to elicit feelings of fear and insecurity within a group setting. The reason that the 
respondents participated in the program, even after great hesitation, was in part, due to their treating physicians recommendation and descriptive experience from other patients: "I was a bit skeptical for a start, but my doctor recommended it and then I thought why not, so I tried it and it was good". Several respondents even suggested that they had wanted a group treatment offer earlier because they then might have escaped developing more severe symptoms of anxiety.

\subsection{Conditions during Treatment}

At each group session there were opportunities to share experiences and to discuss them. This contributed to an increased insight that anxiety may look different among individuals and thus the participants became better at understanding both their own feelings and the feelings of others: "After a while everybody was rather open about their problems and talked about them, and that was good because nothing was really embarrassing. No, and that was a really nice thing about this group". Most of them discovered that they actually contributed to the therapy in the group: "In my opinion we were all therapists in a way, so we weren't trained. That's the way it is, whoever you talk to, your buddy or someone in your family, that person is a like a therapist to whom you ease your heart a little". It was positive that each participant decided how much he/she wanted to share and that the group encouraged the participant to dare to be more open. There was a permissive climate in the group, problems were vented and analyzed. Instructors' attitude was considered important in order for the participant to be recognized. The instructors used the approach to speak calmly, be present, provide space, capture what was important, ask questions, point out the importance of acceptance and convey knowledge that felt solid: "The instructors listened and then they sorted it out. It wasn't like people had different views and that was a problem ... if we couldn't sort it out, they produced pen and paper and showed diagrams or a staircase and then things got clearer for all of us. So everybody did understand and that was because they [the instructors] were so calm and took their time".

\subsection{Experiences of Normalization}

Respondents noticed that other group members also had anxieties and similar thoughts and feelings, this in turn, decreased their feeling of being abnormal and lonely: "It strengthened me, I got stronger when I realized that anxiety, unease and being sad was part of everybody's life. I didn't feel so lonely any more". It was important to know that the reactions they had were not abnormal: "When $I$ came to the group I understood, and they told me, that I wasn't abnormal and my reactions weren't abnorma?'. They understood that others in the group were normal everyday people that also had anxiety related issues: " $P$ ve realized that you can't know from looking at a person if helshe is unwell, or how helshe feels". This changed how they perceived themselves. Group participation made 
new approaches possible.

\subsection{CBT Methods and Strategies}

Through structure with forms and models, respondents gained knowledge about the relationships between behaviors and what maintains a problem or reduces it. Several describe that the information was concrete and clear and that it was helpful: "It was helpful when the instructors used the white-board when we together tried to sort out how to cope. The instructors drew a kind of staircase or a diagram, that made it plain and that was really good". These were found to be easy to use even after the end of the group therapy for analyzing new situations. In addition, the participants were given the opportunity to learn effective techniques like breathing, mindfulness and relaxation which they can use when they feel anxiety. Psycho education was of great importance. Several described how increased knowledge empowered them: "I learnt so much about anxiety, what it means" " got to know more about what's going on in my body, and why". The respondents were given facts and explanations for their illness or diagnosis, which in turn, provided them with a sense of relief, and contributed to the overall credibility of the treatment.

\subsection{Interventions Dealing with Anxiety}

Respondents described how they came into contact with new ways of dealing with anxiety like thought strategies, acceptance, increased knowledge and exposure. They developed an ability to stay calm and meet their thoughts instead of fighting them as before. It was then possible to raise awareness about their patterns and gain understanding of where the anxiety came from, creating a sense of security, and subsequently empowering them: "I have noticed that now I can anticipate when I might risk anxiety". Several respondents mentioned that understanding the trigger to their anxiety both helped them to cope with it as well as to prevent it more effectively: "Now I know how to cope when it happens, and somehow that helps me relax, which means I don't think about it that often". Astonishingly enough, it appeared that respondents learnt that flight is not an effective behavior for diminishing anxiety. Instead they realized that to cure their anxiety they should understanding it, and cure it by accepting it. However, for this to occur, additional knowledge and assistance with alternative behaviors were a necessity. It was also important during the training to complete their homework assignments they got from the instructor. Testing the new learned skills helped them realize that these methods of self-help could be done on their own. This empowered the participants with the responsibility for their own feelings: "You explained a lot very clearly. You explained what anxiety is, and what happens in one's body, in a way that I understood how anxiety works, and that it is possible to do things that are frightening. You said that if one does what is frightening, things that trigger anxiety and one wants to avoid ... if one does it anyway, then the anxiety wanes. Before I never dared lock the lavatory door, but 
now I have exposed myself to it so I can handle it. You drew and wrote a lot, the staircase for instance, and made us understand how anxiety works and that it can be triggered by many things, I, for one, was also scared to use an elevator".

\subsection{Side Effects}

The interviews revealed various affects, that not been trained for during their treatment, but which was described by several respondents as important. It was often about increased trust in other people, which lead to increased transparency when they shared and discussed their own or others' problems. This also led to that the respondents got better and further adequate support from their old networks: "There really is a difference. Yeah ... and I might also take care to look into how I feel. How I really feel. And above all I talk about it with other people, not just family, but close friends and also not so close friends. It is not only the inner circle that knows what has happened or not happened'. Several also described that they learned to say no and set limits and understood the importance of taking care of themselves: "It helped me realize that $1 \mathrm{~m}$ allowed to let go, $I$ don't have to be available. $1 \mathrm{~m}$ worth taking care of myself" .

\subsection{Comments on Treatment}

Respondents had both positive and negative opinions about individual and group therapy. Most of them had no experience with individual treatment, but for those who had they could see the benefits of the group format. Respondents were overwhelmingly positive after their participation. According to them, an important ingredient was related to the group dynamic in that there were more people present than just one-on-one patient therapist session. As more people shared their experiences, the respondents benefitted from additional views from other participants on aspects of themselves and problems they were unaware of (positive and negative), and that interaction contributed to broader insight and understanding: "If $\mathrm{P} m$ seeing a therapist, then there are my words and my feelings and the therapist asks, "How does it feel?" and I reply "It feels like ...". But now, hearing it from another participant "I feel like this" I might think "You do? But I don't. That's interesting." Because it is interesting that you can think or react in so many ways. I can't explain it, I can't exactly remember that feeling, but I do remember that I found it so interesting". Drawbacks were that there was too little time for each and that it could be difficult for some of them to express their views or handle their integrity. Someone expressed doubts about whether it was just group treatment that contributed to change, but thought that there had been other changes or self-help tweaks they did in parallel: "Well, $P d$ probably say so, I think. [that the group therapy has been useful] $P m$ not sure what' $s$ made the difference, but I do feel better today than a year ago, what with the anxiety and all that'. Some point to a reduced need for the group if you have a strong and open network. However it is important to note that breaking group dependence can be a problem if the coping skills to reduce this dependence are not available through a strong and open support network. 


\subsection{Conditions after Treatment}

Several of the interviewees described that they still, "carry the group inside" in different contexts in their normal lives. The general content has been transformed into something individual and that they have been able to integrate the methods learned and use them as natural coping skills to govern their behavior: "I think most of us could apply the strategies on our lives, learn them and apply them our personal situations". Above all, three main methods to deal with anxiety and depression emerged, i.e., processing thoughts, relaxation and breathing techniques: " $P m$ able to put an end to anxiety faster, though, like, thinking, thinking in a different way, positive thinking and mindfulness". These led participants to a greater acceptance and increased feeling of security, which in turn contributed to an inner strength and improved self-esteem: " $P$ ve got kind of thicker skin, I mean I $m$ stronger mentally". Remaining obstacles include reintegration and returning to their various stressful environments and the limitations for permanently embedding the necessary coping skills within the short time frame or shortages. Naturally, their short term gains are critical in motivating their energy, desire and courage to continue a work that is demanding.

\section{Discussion}

The purpose of the study was to investigate which components and interventions contribute to reduce anxiety associated with group treatment with CBT interventions. Using the EPP method (Karlsson, 1995), the study resulted in 41 categories that could then be sorted into 9 more comprehensive index categories, all describing components and interventions that were important for contributing to improved health regarding respondents' anxiety. Further analysis revealed a security process that was initiated through the group treatment, which respondents could then continue to implement and deepen within themselves. Respondents described that before the group treatment, they were worried and scarred. The anxiety was described as fear of being unable to interpret his/her body, lacking knowledge of links between thoughts and behaviors, lacking knowledge as to why they were doing something differently, and feeling alone and different: "I felt like the only one in the world"./ "The group therapy strengthened me; I became stronger when I realized that anxiety, worry and sadness belong to everyday life for most citizens of society. I did not feel as lonely anymore". Respondents seemed to describe the anxiety as a lack of security and that through the treatment they increased their feelings of security which led to an ability to take greater responsibility for your own health and a greater courage to confront the anxiety through the development of different strategies.

\subsection{Three Themes}

The question then becomes how to provide security by means of cognitive behavior group therapy. From the material, three themes emerged that seemed necessary for group treatment and which were also important for creating accep- 
tance and security, namely: 1) Sharing with others, 2) Knowledge and 3) Structure. All respondents addressed these three components and described them as essential, which makes it possible to conclude that they are significant and likely to be of equal importance. To emphasize that all three components are needed, the triad is described as a triangle with similar sides, see Figure 1. In order to understand the meaning of the three components, we will look at the meaning of each one.

Sharing with others. Respondents indicated that it was of great importance to meet others with the same problem. It fulfilled several purposes such as starting to look differently at themselves and their illness, gaining new friends and fellowship, and breaking the isolation that several respondents described as part of the anxiety problem. Several respondents also described how they had previously been weak in setting limits or accepting help from relatives or others, which led to failure to receive the support they needed. Sharing with others reduced feelings of shame and guilt for the respondent but also for the relatives which led to less loneliness and isolation and became a crucial part in increased acceptance of oneself which also increased feelings of security. Example: "Since I ve been able to talk about it, with other people, my feelings have been like confirmed, that they are real to me. Nobody can say "That's not right" any longer, because this is what I feel." “... and you are feeling kind of alone with your thoughts, but you' re backed by someone who isn't a therapist." "Yes, I suppose it's because P ve got some kind of support in return, and some feedback to what I told".

Knowledge. Knowledge given to respondents increased their feelings of security as it increased their overall understanding of anxiety and thus they gained

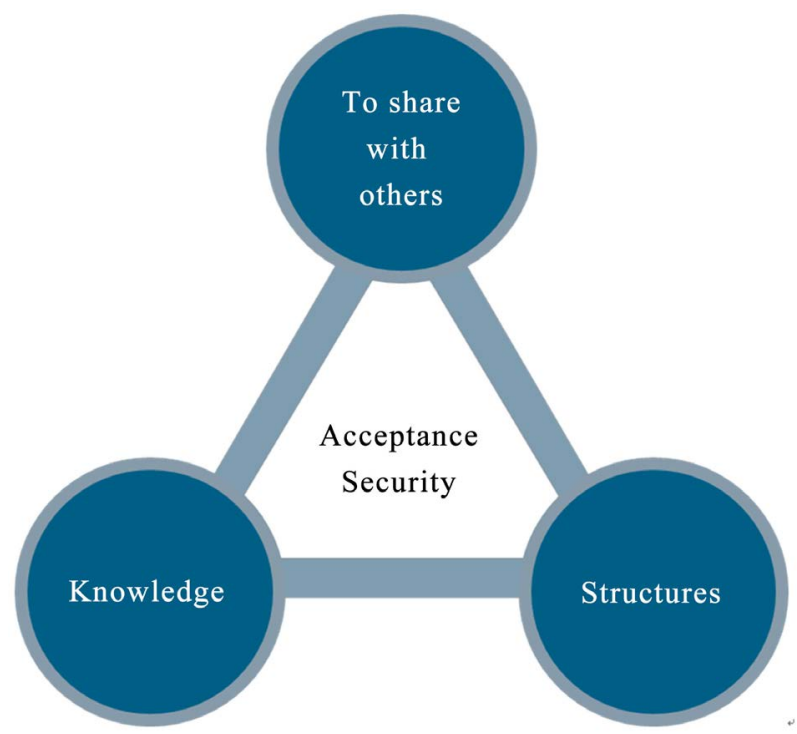

Figure 1. The group creates a secure environment (external security) by providing structure, knowledge and sharing with others that enable the group participant to train and develop feelings of acceptance and security. 
better insight into different causal relationships. They gained greater knowledge of the connections between health, lifestyle, thoughts, behaviors and the anxiety they experienced. Respondents described that they previously did not had the tools for changing their situation and that it was of great importance to get new ones, such as mindfulness, situational analysis techniques, and breathing. They developed insights on how to confront difficulties instead of avoiding them. It was important that the instructors were knowledgeable in the methods they taught. Respondents had previously experienced powerlessness, but thanks to new knowledge they could take command over their lives. Example: "You explained what anxiety is, and what happens in one's body, in a way that I understood how anxiety works, and that it is possible to do things that are frightening. You said that if one does what is frightening, things that trigger anxiety and one wants to avoid ... if one does it anyway, then the anxiety wanes." " P ve learnt to recognize the early signs, so I can handle it. I didn't know that when I came to the group, I had no idea whatsoever, but now I know".

Structure. In most cases, the size of the groups gave enough room for everyone to take place in a way that they previously not done. The instructors' attitudes and how they handled each participant's needs also became a role model that provided structures and acceptance that the participants could copy and practice in their own lives. Several respondents described how they previously had difficulty in self-assertion and that the group treatment became an opportunity to see how such an approach could work in practice and then have the opportunity to practice it out-side the group. Example: "The instructors kept track of time and told us what to do, so we could relax and don't bother about anything. I was very comfortable with that". "“The instructors listened and then they sorted it out. It wasn't like people had different views and that was a problem ... if we couldn't sort it out, they produced pen and paper and showed diagrams or a staircase and then things got clearer for all of us. So everybody did understand and that was because they [the instructors] were so calm and took their time".

\subsection{The Security Process}

Data showed a basic experience of insecurity among respondents at group start. Through the treatment and through the instructors, a sphere of security was created in the group. With the help of structure, increased knowledge and an increased inclination to share with others, the respondent gained more insight and understanding of his/her own ability. These three main components were supplied from outside. Through practical demonstrations and exercises, performed repeatedly in the group and at home, participant could successfully integrate new knowledge and new perspectives. A security process was established where the perceived safety of the group, "outside the individual", could be moved to "inside the individual", see Figure 2.

The crucial factor for starting the security process was that the respondent accepted group treatment. Sharing with others became the first step in the process, 


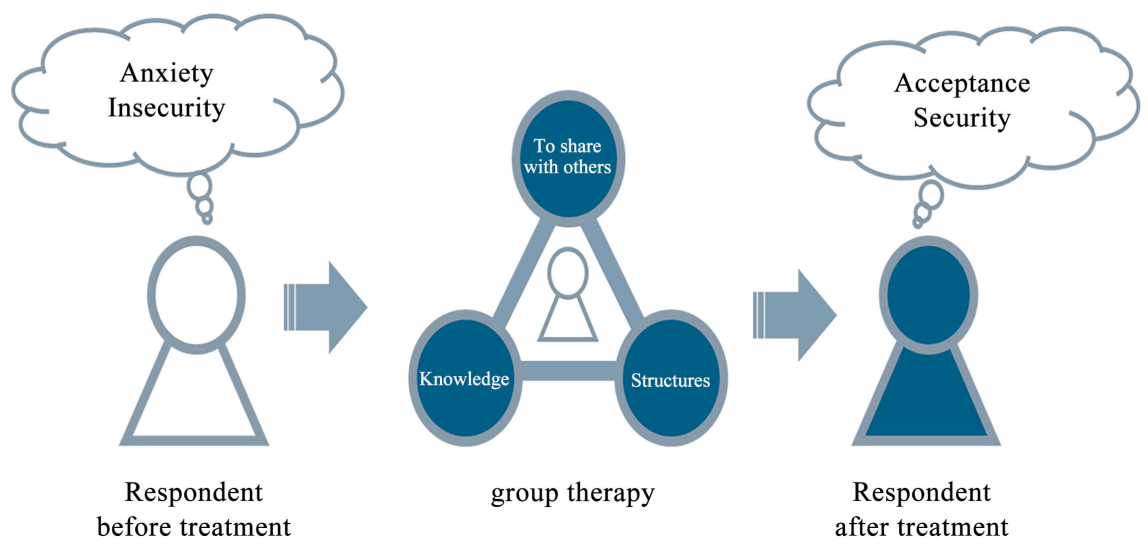

Figure 2. By externally adding the three security components, respondents could integrate these and experience acceptance and security (internal security). A security process was established where the perceived security of the group, "outside the individual", could be moved to "inside the individual".

which meant that the respondent became increasingly exposed without experiencing negative effects, which created increased trust and acceptance. New knowledge that was continuously introduced gave opportunities to broaden the repertoire, both in terms of reflections and behaviors, which empowered the respondent. To observe how participants handled different situations and instructors' contributions with new knowledge created structures was integrated. This brought about the change that consisted of a sense of security. When the group ended, the group's dynamics and structures also disappeared. Interestingly, the respondents experienced that the security created in the group now after the therapy remained as an asset in them, which has led to acceptance and a significantly reduced experience of anxiety.

\subsection{Final Remarks}

A review of studies with CBGT (Cognitive Behavior Group Therapy) provides evidence that the three safety components we have identified in this study have also been highlighted by previous research (e.g., Bieling et al., 2006; Carey et al., 2007; Sandahl, 2008; Söchting, 2014). It is agreed that the group's strength is that participants share experiences and become part of a context that breaks the isolation. Söchting (2014) wrote about the participants' perception of not being alone with their experiences and that the group contributes to a sense of belonging and breaking social isolation. As in the current study, it appeared that openness, acceptance and hope replaced anxiety and shame by meeting the participants (Söchting 2014). Sandahl (2008) emphasized that participation in the social system contained in a group is a central part of the therapeutic intervention.

Studies that have analyzed participants' own experiences have also highlighted the other two security components i.e., knowledge and structure. New knowledge leads to effective copying skills which are necessary parts in the therapy (Carey et al., 2007). Important was a learning process that is practical and inter- 
active. Binder and associates (2009) reported that the crucial event in a therapy was that the patient was motivated and that the patient himself/herself was active while the therapist gave the structures that enabled constructive work to take place. An additional important aspect that contributed to satisfaction and change was that the problems could be normalized by the therapist explaining how they occurred. Clear goals, exercises and exposure are necessary for healthy behaviors to occur (Ingvarsson et al., 2014). Sandahl (2008) has a broader perspective that also includes the exchange of knowledge and learning in the group and describes that the interviewees point to the importance of exchanging information and advices in order to see similarities and differences that contribute to the learning of different individuals.

The current study revealed how the three components, Sharing, Knowledge and Structures, contributed to the feelings of acceptance and security. The significance of perceived feeling of security as an expression of remission is in line with previous quantitative study of borderline patients (Norlander, Ernestad, Moradiani, \& Nordén, 2015) which defined security in accordance with Segesten (1994) as "a perceived feeling of being free of worrisome or threatening phenomena ". The concept of remission can be described as the patient developing a good enough function in order to function well in society with the help of various strategies (Niklasson, Norlander, Niklasson, \& Rasmussen, 2017). Stabilization at the level of remission with improved quality of life as a consequence also constitutes a better starting point for an even greater recovery (Weiden, Aquila, \& Standard, 1996). Perceived feeling of security can be divided into external security and internal security. External security is situation-related security (Segesten, 1994) and developed in the current study as illustrated in Figure 1. Internal security is a more complicated phenomenon, but typically occurs together with acceptance as illustrated in Figure 2.

However, further qualitative research is required on patients' experiences of CBGT. Such a project may be to provide more evidence for what should be included in definitions of remission in connection with psychiatric diagnoses such as anxiety and depression. Furthermore, it would be of interest to investigate how patients' experiences of safety can monitor the design of the therapy. Further research could also study those patients who remain at clinical anxiety levels despite completed treatment, thus gaining a deeper understanding of the problems in order to identify the remaining obstacles.

\section{References}

American Psychological Association (2006). Evidence-Based Practice in Psychology. APA Presidential Task Force on Evidence-Based Practice. Washington DC: APA.

Angantyr, K., Rimner, A., Nordén, T., \& Norlander, T. (2015). Primary Care Behavioral Health (PCBH) Model of Integrated Care: Perspectives of Outcome, Client Satisfaction, and Gender. Social Behavior and Personality, 43, 287-301.

https://doi.org/10.2224/sbp.2015.43.2.287

Bennett-Levy, J., Richards, D. \& Farrand, P. (2010). Low Intensity CBT Interventions 
Revolution in Mental Health Care. In J. Bennett-Levy, D. A. Richards, P. Farrand, H. Christensen, K. M. Griffiths, D. J. Kavanaugh et al. (Eds.), Oxford Guides in Cognitive Behavioural Therapy. Oxford Guide to Low Intensity CBT Interventions (pp. 3-18). New York: Oxford University Press.

Bieling, P. J., McMaster, U., Hamilton, O. T., McCabe, R. E., Antony, M. M., \& Antony, M. M. (2006). Cognitive-Behavioral Therapy in Groups. New York: Guilford Publications.

Binder, P. E., Holgersen, H., \& Nielsen, G. H. S. (2009). Why Did I Change When I Went to Therapy? A Qualitative Analysis of Former Patients' Conceptions of Successful Psychotherapy. Counseling and Psychotherapy Research, 9, 250-256. https://doi.org/10.1080/14733140902898088

Butler, A. C., Chapman, J. E., Forman, E. M., \& Beck, A. T. (2006). The Empirical Status of Cognitive Behavioral Therapy: A Review of Meta-Analyses. Clinical Psychology Review, 26, 17-31. https://doi.org/10.1016/j.cpr.2005.07.003

Carey, T. A., Carey, M., Stalker, K., Mullan, R. J., Murray, L. K., \& Spratt, M. B. (2007). Psychological Change from the Inside Looking Out: A Qualitative Investigation. Counselling and Psychotherapy Research, 7, 178-187.

https://doi.org/10.1080/14733140701514613

Chamberlain, L. D., \& Norton, P. J. (2013). An Evaluation of the Effects of Diagnostic Composition on Individual Treatment Outcome within Transdiagnostic Cognitive-Behavioral Group Therapy for Anxiety. Cognitive Behaviour Therapy, 42, 56-63. https://doi.org/10.1080/16506073.2012.748090

Dugas, M. J., Ladouceur, R., Léger, E., Freeston, M. H., Langolis, F., Provencher, M. D., \& Boisvert, J. M. (2003). Group Cognitive-Behavioral Therapy for Generalized Anxiety Disorder: Treatment Outcome and Long-Term Follow-Up. Journal of Consulting and Clinical Psychology, 71, 821-825. https://doi.org/10.1037/0022-006X.71.4.821

Edebol, H., Bood, S.Å., \& Norlander, T. (2008). Case Studies on Chronic Whiplash Associated Disorders and Their Treatment Using Flotation-REST (Restricted Environmental Stimulation Technique). Qualitative Health Research, 18, 480-488. https://doi.org/10.1177/1049732308315109

Hawley, L. L., Padesky, C. A., Hollon, S. D., Mancuso, E., Laposa, J. M., Brozina, K., \& Segal, Z. V. (2017). Cognitive-Behavioral Therapy for Depression Using Mind over Mood: CBT Skill Use and Differential Symptom Alleviation. Behavior Therapy, 48, 29-44. https://doi.org/10.1016/j.beth.2016.09.003

Heimberg, R. G., Salzman, D. G., Holt, C. S., \& Blendell, K. A. (1993). Cognitive-Behavioral Group Treatment for Social Phobia: Effectiveness at Five-Year Follow-Up. Cognitive Therapy and Research, 17, 325-339. https://doi.org/10.1007/BF01177658

Ingvarsson, T., Nordén, T., \& Norlander, T. (2014). Mindfulness-Based Cognitive Therapy: A Case Study on Experiences of Healthy Behaviors by Clients in Psychiatric Care. Open Journal of Medical Psychology, 3, 390-402. https://doi.org/10.4236/ojmp.2014.35041

Jervelycke, A., Larsson, B., \& Norlander T. (2017). Attitudes to Group Assessments: Prospective Psychotherapists' Experiences of Being Assessed by Fellow Students. Open Journal of Medical Psychology, 6, 179-196. https://doi.org/10.4236/ojmp.2017.63015

Karlsson, G. (1995). Psychological Qualitative Research from a Phenomenological Perspective. Stockholm: Almqvist \& Wiksell International.

Lilja, J. L., Broberg, M., Norlander, T., \& Broberg, A. G. (2015). Mindfulness-Based Cognitive Therapy: Primary Care Patients' Experiences of Outcomes in Everyday Life and Relapse Prevention. Psychology, 6, 464-477. https://doi.org/10.4236/psych.2015.64044 
Malterud, K. (2001). Qualitative Research: Standards, Challenges, and Guidelines. The Lancet, 358, 483-488. https://doi.org/10.1016/S0140-6736(01)05627-6

Niklasson, M., Niklasson, I., \& Norlander, T. (2010). Sensorimotor Therapy: Physical and Psychological Regressions Contribute to an Improved Kinesthetic and Vestibular Capacity in Children and Youth with Motor Difficulties and Problems of Concentration. Social Behavior and Personality, 38, 327-346. https://doi.org/10.2224/sbp.2010.38.3.327

Niklasson, M., Norlander, T., Niklasson, I., \& Rasmussen, P. (2017). Catching-Up: Children with Developmental Coordination Disorder Compared to Healthy Children before and after Sensorimotor Therapy. PLoS ONE, 12, e0186126.

https://doi.org/10.1371/journal.pone.0186126

Nordén, T., Eriksson, A., Kjellgren, A., \& Norlander, T. (2012). Involving Clients and Their Relatives and Friends in the Psychiatric Care: Case Managers' Experiences of Training in Resource Group Assertive Community Treatment. PsyCh Journal, 1, 15-27. https://doi.org/10.1002/pchj.1

Norlander, T., Blom, A., \& Archer, T. (2002). Role of High School Teachers in Swedish Psychology Education: A Phenomenological Study. The Qualitative Report, 7, 1-17.

Norlander, T., Ernestad, E., Moradiani, Z., \& Nordén, T. (2015). Perceived Feeling of Security: A Candidate for Assessing Remission in Borderline Patients? The Open Psychology Journal, 8, 146-152. https://doi.org/10.2174/1874350101508010146

Sandahl, C. (2008). Gruppens Terapeutiska Potential. In B. Philips, \& R. Holmqvist (Eds.), Vad är verksamt i psykoterapi? (pp. 99-119). Stockholm: Liber.

Segesten, K. (1994). Patienters upplevelser av trygghet och otrygghet. Göteborg: K \& K Förlag AB.

Shaffer, C. S., Shapiro, J., Sank, L. I., \& Coghlan, D. J. (1981). Positive Changes in Depression, Anxiety and Assertion Following Individual and Group Cognitive Behavior Therapy Intervention. Cognitive Therapy and Research, 5, 149-157. https://doi.org/10.1007/BF01172523

Söchting, I. (2014). Cognitive Behavioral Group Therapy: Challenges and Opportunities. Chichester, UK: John Wiley \& Sons. https://doi.org/10.1002/9781118510261

Weiden, P., Aquila, R., \& Standard, J. (1996). A Typical Antipsychotic Drugs and Long-Term Outcome in Schizophrenia. Journal of Clinical Psychiatry, 57, 53-60.

World Health Organization (2014). Social Determinants of Mental Health. Geneva: World Health Organization \& Calouste Gulbenkian Foundation.

Zigmond, A. S., \& Snaith, R. P. (1983). The Hospital Anxiety and Depression Scale. Acta Psychiatrica Scandinavica, 67, 361-370. 